\title{
Trigger Questions: \\ Their Role In Problem Based Learning; Do They Add To The Quality Of Interactive Business Case Study Solutions?
}

\author{
James Gallagher, (E-mail: J.Gallagher@napier.ac.uk), Napier University, Scotland, UK
}

\begin{abstract}
This paper examines, not the use or appropriateness of business case studies in the learning process but rather, the efficacy of the questions that trigger the learning process within the case study.
\end{abstract}

\section{INTRODUCTION}

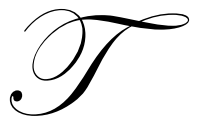

he most effective learning is grounded in experience - learning by doing. However, in business schools it is unlikely that many of the students will have had any great exposure to real life business experience. Moreover, the depth of their experiences is often correlated with the level of the course they are embarking on. Furthermore, it would probably be true to say that in terms of the student body they are generally at the beginning of their careers and their experiential exposure is further limited. To ameliorate these limitations recourse is often made to business case studies that simulate real life situations. Arguably, cases are the most effective and the most efficient way for learning to take place. These cases place the student in positions where they have to make decisions, deal with the consequences of those decisions, and learn from the real mistakes they make. The thrust of this paper is to examine, not the use or appropriateness of business case studies in the learning process but rather, the efficacy of the questions that trigger the learning process within the case study.

The stimulus for this paper was simple I had carried out two pilot questionnaires one the case study and student perception and the other a multimedia case study and its technology acceptance. From these questionnaires certain issues arose that made me question how I was developing and teaching with case studies. Although the primary focus in this paper is on the business case study format, attention is equally given to the contribution of the constituent elements of e-case development. For the business case study my contention is simply that asking the right questions is fundamental to achieving satisfactory case study teaching and learning as it is these questions that frame the discovery and learning process. However, their efficacy may be augmented by the delivery platform, in this case e-delivery. In this instance embedded, online, interactive business case studies.

The case study, once written, forms the core narrative from which the interactive script will be produced and against which the interactive materials will be applied. The application of these multimedia techniques with their inherent flexibility appears to offer the best potential for ameliorating some of the problems associated with the use of business case studies:

1. not all students learn at the same rate,

2. do not all start from the same educational base - in the area of business policy in particular they are likely to come from a range of disciplines,

3. nor are all students as ready to contribute to class discussion. 
For students the important feature of the interactive business case study is the capacity to control the pace and direction of learning. At present, students are confronted by the structures of a predetermined teaching programme that is usually followed in sequence. In multimedia format they can choose the areas on which they wish to concentrate and, in the strategic management field, they can review theory and its practical applications in a less stressful environment.

For the business case study developer multimedia applications encourages imaginative presentations of theoretical material. Concepts can be presented on screen in ways which are not possible on the written page. In the same way truly interactive tutorial material can be designed in which students receive feedback on answers that incorporates explanations for errors and directions for remedial work. There is also considerable scope for 'what if' modelling and competitive decision-making. But, in order to unlock the full potential of both the student and the case study and its augmenting application appropriate trigger questions must be asked.

\section{THE LIFE CYCLE OF A CASE STUDY}

It is crucial when developing business case studies to keep in mind your audience (Diagram 1) and its dynamics when developing a business case study. There are five areas which have to be considered - level; target group; complexity; currency and outcomes. Taking LEVEL as an example although I have not carried out the research yet a case, perhaps spurious but yet with a kernel of truth, can be made for case studies to be developed on the basis of length.

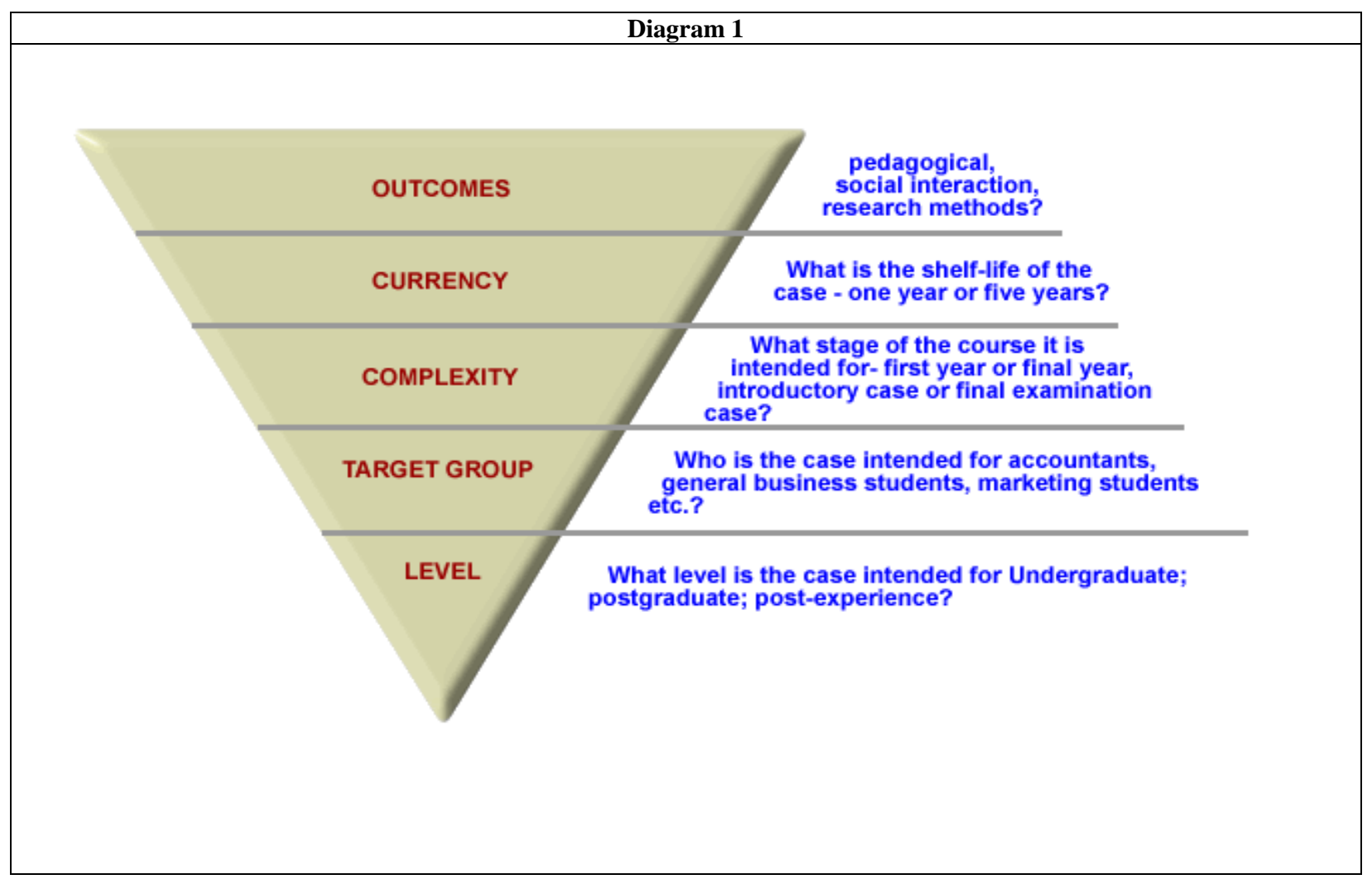




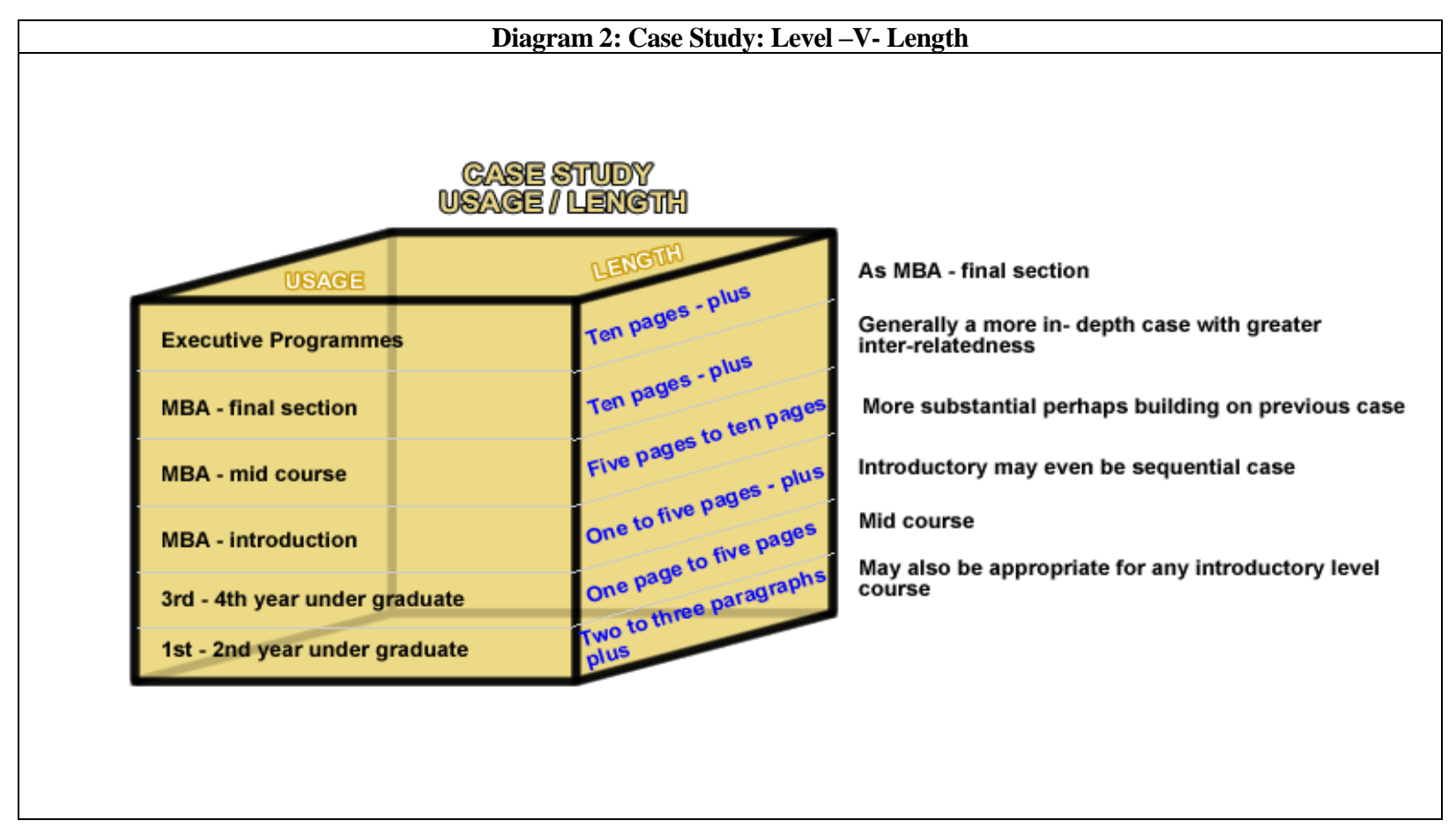

In today's educational environment students are facing increasing demands on their time and as a consequence seek more pithy, focused and direct case studies. Undergraduates in particular, more often than not, have part time and often full time jobs which manifests in less preparation time for tutorials. Long case studies of the older Harvard type of thirty pages plus may not now engage the concentration span of today's students whether they are first year under graduates or participants on an executive programme.

These areas will impact and colour the questions set for the case study and its use for example; who is the target audience and at what level of the educational process are they? The questions set for undergraduate will be substantially different from those used with post-experience. Moreover, on each of the above counts the interactive case study has the potential to attain a higher level of achievement than does the paper based case study on its own for example, the user faces a less stressful learning environment one which is under his or her control when on-line interactive materials is introduced.

The practice, at university is for the lecturer to develop, in house, live business case studies based on real companies. These case studies are used initially as part of the final examination on Strategic Management courses and, consequently, are usually no more than six weeks old when distributed first to the students. This helps to negate the growing problem of plagiarism in that any likelihood of the student finding a pre-worked or published solution to the case is almost non-existent. The students are given the case four weeks prior to the examination which is an open book type and is of two hours duration. The questions are not seen by the students until they enter the examination room.

The case can be used with the following year's students as a primary piece of assessed coursework. At this time the efficacy of the case as a teaching medium is significantly enhanced by inviting into the class a guest speaker from the company, ideally the chief executive or finance director, to address the issues and problems confronted by management and the actions and solutions taken. This allows dialogue between practising manager and student to take place after their work has been submitted for assessment.

In subsequent years the case can be used in tutorial as a teaching vehicle. If it proves a popular and stimulating case then its usage will be extended. 
At this juncture there is little formal pressure on the lecturer to provide guidance notes to accompany the case study. Consequently, the case is in effect half, or less than half, finished. However, if the case author seeks academic recognition for his/her endeavours then a guidance note is a prerequisite.

The case, once it has been tested with a class, can be brought to a wider audience by publishing it through the European Case Clearing House (ECCH) (see diagram 2) for general education and training publication. It may also be submitted to the European Foundation for Management Development Case Competition. Both the ECCH and the EFMD expect each case to be accompanied by a comprehensive teaching note and, where possible, a background or industry note.

Finally, it may be included in a text book or published on a commercial case study web site.

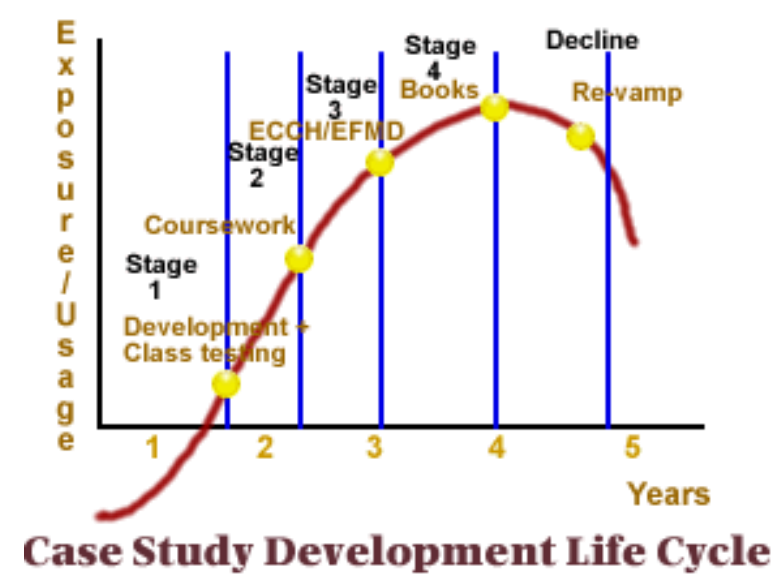

Diagram 2

The business case study, as it is commonly viewed, is in general, a problem-solving, teaching and learning methodology geared to resolving complex; unstructured; problems presented to students for solution. In essence the application of this methodology should add value the student's learning experience. However, to do this we must enhance their abilities by developing the experiences which draw on and extend their knowledge, aptitude, and attitudes.

The question is, does teaching by case study achieve this and if so, then to what extent? Two pilot surveys, one on student's attitude to case studies and the other on a technology acceptance model (TAM) based on e-delivery of case studies, were carried out with MBA/MSc students that gave the following results.

\section{Student Satisfaction Responses To Likert Scale Questions}

The charts below show student responses to the Likert Scale questions. The first chart shows responses by all students on case study usage while the second and third details responses from students on e-delivered tutorial support and general assessment of the e-application. Overall, fifty-five students completed the pilot questionnaires. Five is the highest possible score on the charts and one is the lowest 

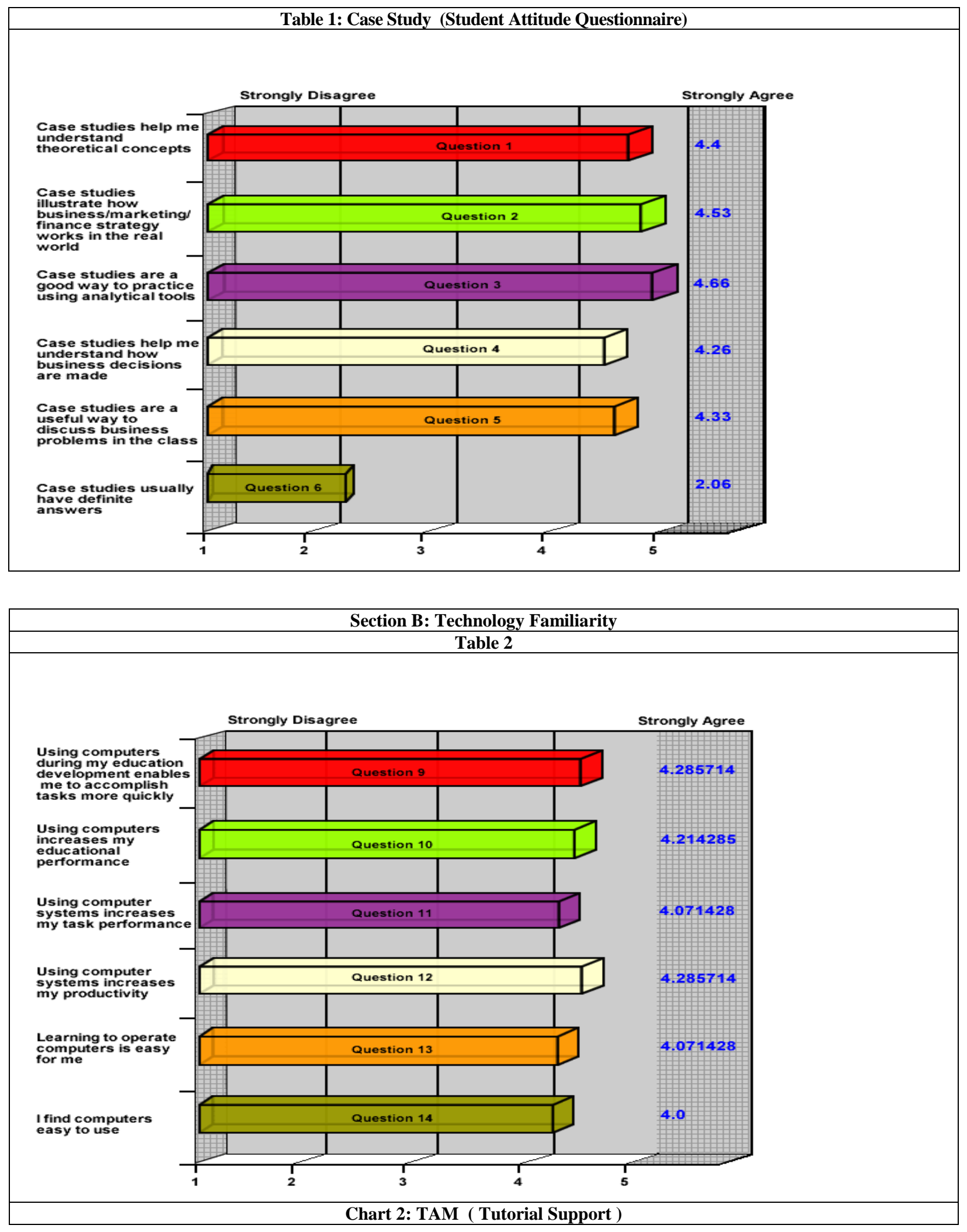


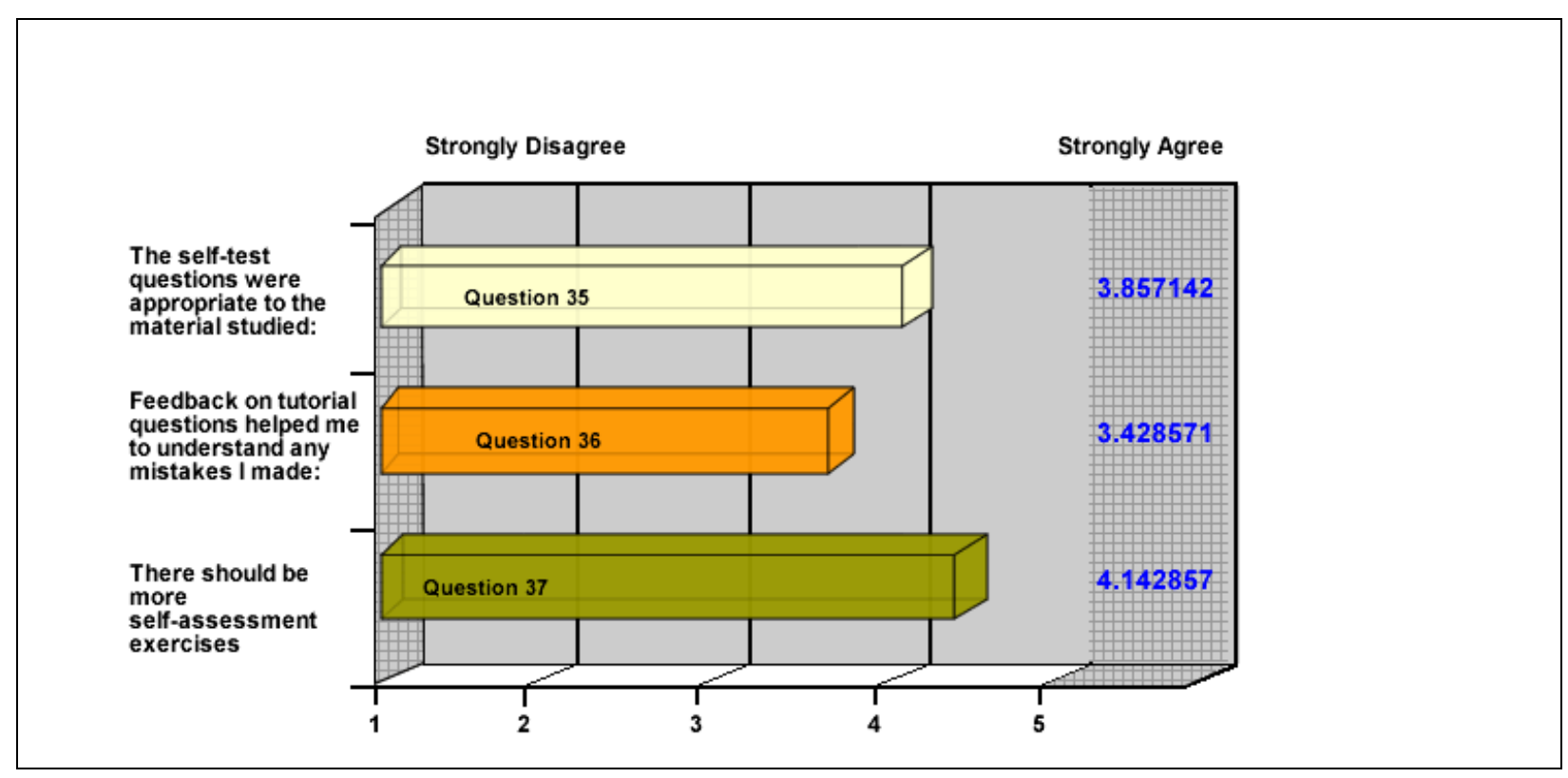

However, even once the case study has been developed and its interactivity constructed the route from problem identification to solution generation on the part of the student is not always a clear one.

Biggs and Collins developed the SOLO taxonomy (Structure of Observed Learning Outcomes) as a means of describing the level of increasing complexity in a student's understanding of a subject, through five stages:

1. Pre-structural: here students are simply acquiring bits of unconnected information, which have no organisation and make no sense.

2. Unistructural: simple and obvious connections are made, but their significance is not grasped.

3. Multistructural: a number of connections may be made, but the meta-connections between them are missed, as is their significance for the whole.

4. Relational level: the student is now able to appreciate the significance of the parts in relation to the whole.

5. At the extended abstract level, the student is making connections not only within the given subject area, but also beyond it, able to generalise and transfer the principles and ideas underlying the specific instance.

The SOLO taxonomy may readily be applied to the business case study. Students normally come to these fresh with little or no exposure to this form of teaching and learning. Their first experiences can often be traumatic as they are confronted with an unstructured body of work (pre-structural) against which they have to bring some form of order by systematising its component parts. From this process some form of prioritisation (unistructural) is attempted as the student tries to rationalise the information he/she has before them. At this point the student is still engaged in surface learning as linkages have not yet been made. However, once the linkages between the individual elements in a case are established the holistic nature of the case study begins to emerge (multistructural) e.g. juxtaposing a time-line of events against share price movement allows critical event analysis to begin. 


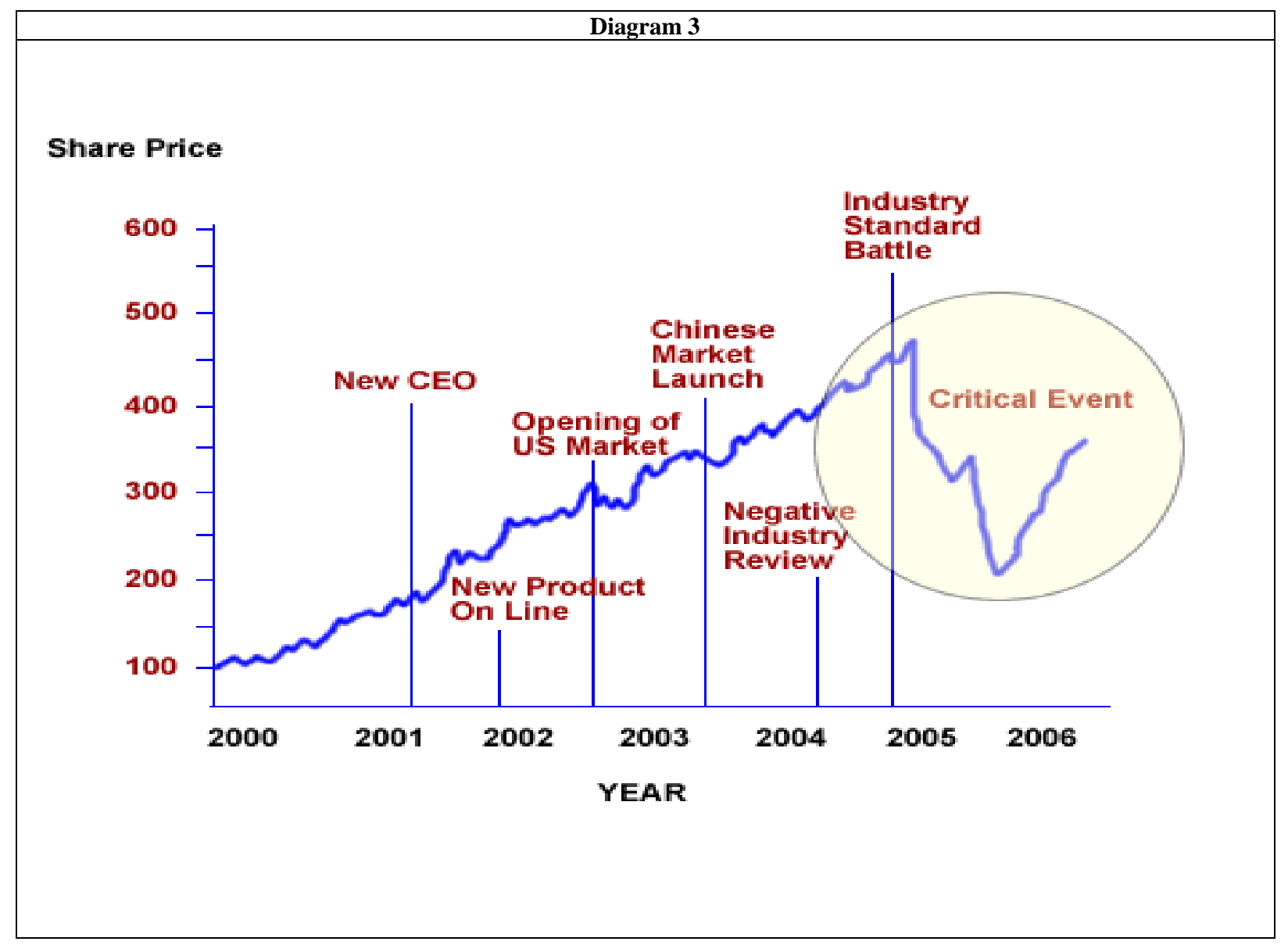

From the critical event analysis the student should be able to appreciate the fact that the new CEO has overseen the launch of a new product into both the US and Chinese markets but has experienced negative reviews within the industry and is facing a battle with its competitors for the industry standard of production (see diagram 3 ). The outcome is that share price has dropped by nearly sixty percentage points indicating that the market does not have confidence in the new product becoming the industry standard (relational level). Subsequently however, the share price rallies indicating perhaps, that some form of alliance has been made with its competitor?

Nevertheless, for the student remedial action is now called for and he/she will draw upon his/her tools of analysis and experience to plot a course of action (extended abstract) to be undertaken by the company.

So far so good! But are we really on the right track? Conventional wisdom would claim that there is no definitive solution to a case study. If this is correct then what are we examining? For the lecturer, do we take it that his/her solution is the correct one and it is against this that we measure student answers? Surely not! It would be presumptuous of us in the extreme to assume that our solution to a problem that, by its very nature and presentation is light on definitive information, is more correct than those of our students.

The roots of this work are firmly grounded in an earlier paper I wrote (Gallagher 2006) which threw up a question I had never before asked myself but had always been niggling at the back of my mind - are we asking the right questions in case study teaching? The immediate answer was - probably not!

Perhaps then, we should redefine what we are trying to achieve in case study teaching. Are we really trying to get students to solve problems or are we trying to arm students with weapons and experiences that allow them to 
contextualise and substantiate the stance they take in their answers? If we dismiss the idea of definitive solutions and instead concentrate on the issues embedded in the case study, then perhaps we can achieve a more efficacious learning experience for the student through allowing them to self develop, triggered by the questions we ask (Gallagher 2006).

Self development by students is one thing but I do not believe that we have quite reached the stage where we can allow the student full self assessment. At the end of the day the lecturer still has to assess the student. To facilitate this, assessment may be classed as diagnostic, formative or summative. In its rawest form the business case study is designed to facilitate learning and the purpose of assessment is to check that learning has taken place. So, if the role of the business case study is to achieve learning then formative assessment or 'assessment for learning' (Sorenson, 2000) should rightly be the mechanism to facilitate this. However, when the business case study is integrated with on-line, interactive materials both diagnostic and summative assessment may be embedded in the case study matrix and accessed by both the lecturer and student as and when desired (Gallagher 2004) and within this there will be high degree of self assessment.

\section{BUSINESS CASE QUESTIONS CONTEXTUALISED}

For me this manifested itself in the realisation that students are not passive recipients of knowledge. They do not simply soak-up and absorb information and concepts. Nor does knowledge simply download directly into their brains. They are sentient with a desire to use their accumulated knowledge and experience not plug and play automatons. Case studies allow them to use theory in anger whilst testing the boundaries of their abilities, knowledge and comprehension. Interactive systems further allow the student to test and be tested, on an iterative basis, calling on their comprehension of the theory and situational parameters confronting them. The simple ability to provide a quiz or test to the student that allows them to check theory if they answer wrongly is an invaluable tool. It allows the student to test himself when and where he wants, reduces stress, as there is no embarrassment should he get it wrong, and provides reinforcing stimuli when he gets it right (see Diagram 4). Moreover, there must be a perceived solution for the case study problem. It may not be the definitive one but it must be present and addressed as it provides academic closure for the student. These solutions are critical for producing a holistic teaching experience for the student and are based on issue identification and then asking the right trigger questions.

The issue here then, is what are the right or trigger questions? In case study development and usage it is tempting to ask the simple (almost standard) questions e.g. 'With the help of a SWOT analysis assess the position of the company' or 'Using tools of analysis with which you are familiar evaluate the position of the company for meeting its challenges.' It is debatable whether these questions, though pertinent but stripped to their essentials, have the richness to act as triggers for generating the most creative case solutions. Furthermore, there is always the danger that asking the wrong question will diminish the effectiveness of the learning process as it takes just as much effort on the part of the student to answer a useless question as it does a useful one.

Essentially, we are trying to get the student to do the things we want him/her to do. In addition, we are trying to ensure that the questions set before the students cause them to effectively engage their understanding, skills, and reasoning. These, when exercised will ultimately manifest in the responses and answers submitted by the students which will, in turn, show that they are indeed doing (or not doing) the things we want them to do. Consequently, the aim should be to create questions that naturally fit with the context and content of the case study so that the issues central to the case study and its associated theory are also central to the case context (Taber, 2003).

\section{TRIGGER QUESTIONS AND DEEP LEARNING INITIATION}

Diagram 4 combines Kolb (1984) who described the experiential learning model as consisting of four stages; concrete experiences, observation and reflection, formulation of abstract concepts, and generalisations and testing implications of concepts in new situations.

If we wish to avoid gross errors of judgement in case analysis then forget definitive solutions and focus on -problem definition and what are the issues. 


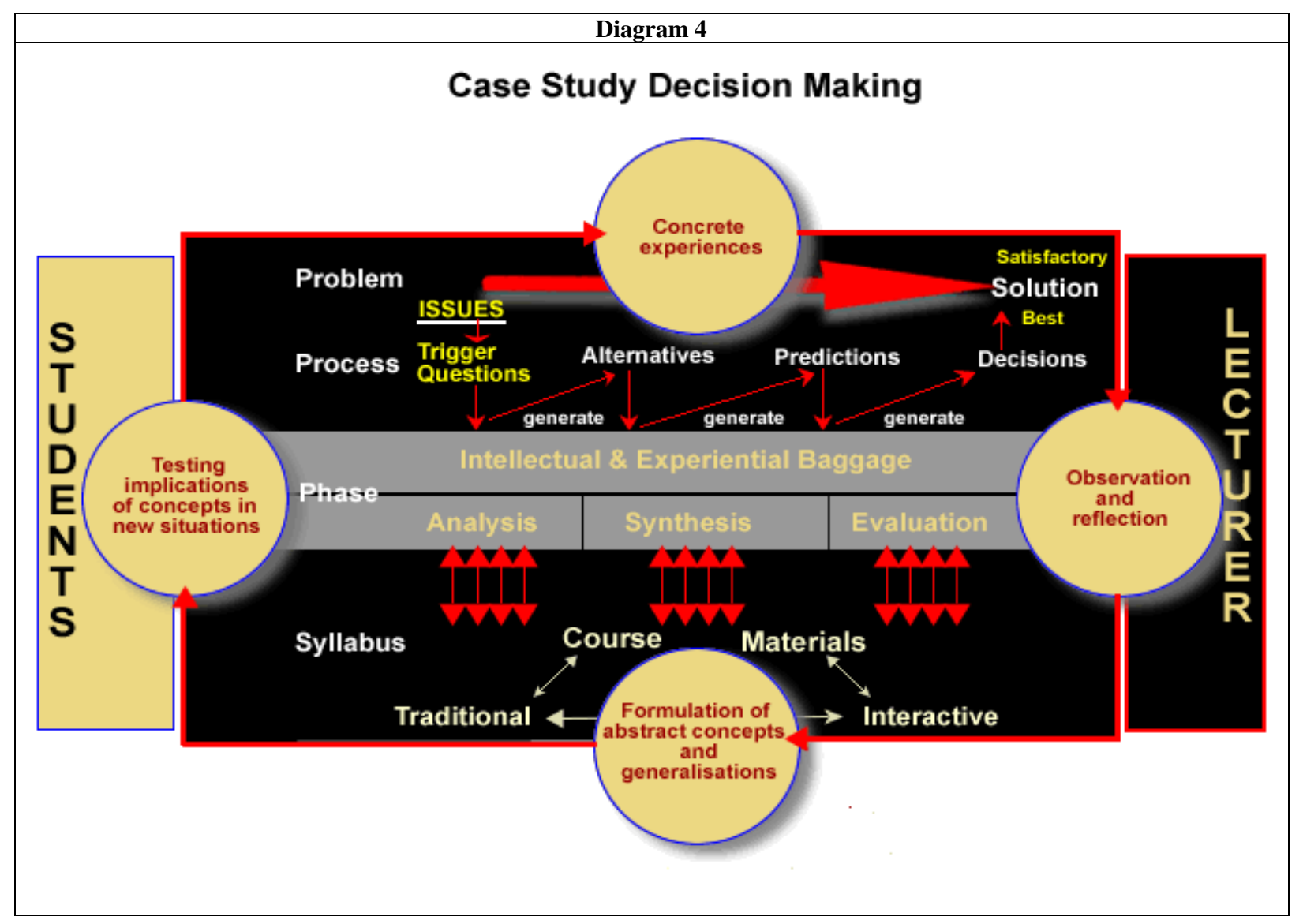

This is probably the most crucial part of case analysis for, as in life, we often fail to see the real issue or problem and as a consequence devote our finite resources of time and effort to solving the wrong problem.

For example diagram 4 shows the case study decision-making process which is driven by the lecturer who develops a business case study, creates the teaching guide and trial runs it with the student body. Within this process the course materials are developed and linked interactively with the case study and its teaching guide these are then linked with the central area of diagram 4 concerning the deep learning cycle. Taking each element in Diagram 4 it is possible, though a little artificial, to show the procedural stages associated with decision-making.

\section{The Student/Lecturer}

The starting point in Diagram 4 is the relationship between the student and the lecturer. This relationship is not a distant one. The audience he targets the business case study at will influence the lecturer. He will be aware of the components underpinning the business case study (see Diagram 1) and will adjust his approach to account for them. Simply put business case study questions should not be set in isolation of the wider contextual frame of reference.

\section{The Problem}

The Kolb model, as depicted in diagram 4 (concrete experiences; observation and reflection; formulation of abstract concepts; and testing implications) when applied to business case study development, helps the lecturer, to broadly focus his/her attention on each stage of the model and design appropriate questions that ensure that these encourage student reflection, conceptualisation and ways of testing ideas. 
Subsumed below this constructivist, experiential learning aspect is the more structured constructs of the problem, the process, the phase and the syllabus. Here the problem can be viewed as a holistic matrix from which a solution will be nurtured and developed. The corollary would be to view the problem as the grit embedded in the oyster's matrix from which a pearl of a solution will be nurtured and developed. The quality of this pearl will depend on the environmental factors (internal and external) that act upon it. However, identification of the problem in the first instance may prove to be the primary difficulty (Wertheim, 2006) for both the lecturer and the student. Simply put what are the key issues in the case study; who is the decision maker in the case; is there a critical decision or a critical decision point? In this instance the key is the identification of pivotal issues within the case study. By their very nature these issues will be broad brush but will encapsulate the essential dynamics of the situation embedded in the case. Once the key issue(s) have been identified by the lecturer he/she can begin to build upon these to foster student deep learning on the way to solution generation.

1. Is it clear what issue is being addressed? (why was it chosen?)

2. Is that issue relevant?

3. Have all the relevant options been considered (in light of the problem definition)?

\section{The Process}

Often lecturers in strategic management will tell their students that there are three broad questions that may be asked of any case study:

1. Where are we now?

2. Where are we going?

3. How do we get there?

In attempting to answer these questions it is hoped that the student will adopt a holistic approach. The objective here is to bring together all the available information in such a way as to allow its examination in the most meaningful and productive terms. In each of these areas there are a range of questions or points that can act as a framework for analyses. They can conveniently be listed as criteria to be addressed, and consequently this allows a methodology to be built up which can be used in any case study or business situation.

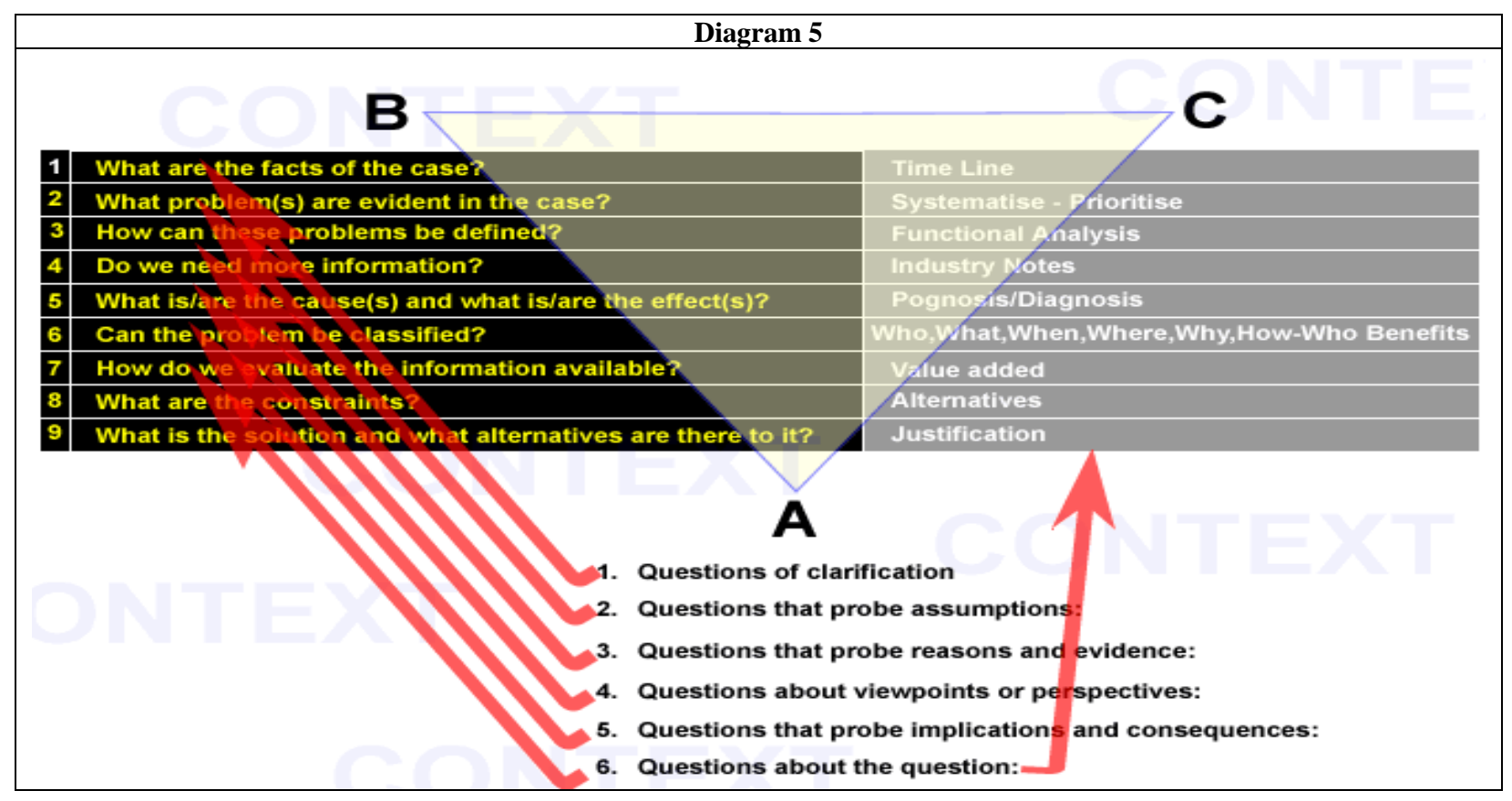


List A (Diagram 5) gives some indication of the category of question form that the lecturer might think of to direct the student towards deep learning, as shown in the phase section of diagram 4 - Analysis, Synthesis and Evaluation.

These A question categories will often find expression in Diagram 5 B which gives a sample of questions that may be asked about a case study with a high degree of specificity and addressing surface level learning of Knowledge, Understanding and Application and may therefore encourage learning of surface detail rather than an appreciation of underlying concepts. Some of the tools and responses to these B questions are grounded in the practical applications of $\mathrm{C}$, though in themselves these may be viewed by the lecturer as the basis for developing further questions.

Furthermore, these questions still tend to be broad brush in nature and do not necessarily direct the student's focus to context. However, they do create a frame of reference upon which the student can hang their thoughts. From this the student can progress to the discovery of pedagogic relationships.

The process then, is the means by which solution generation is achieved. The fundamental action in successfully directing students to a satisfactory solution to the case problem(s) is the asking of trigger questions. These questions should stimulate the student to draw upon his/her intellectual and experiential baggage whilst beginning the deep learning process of analysis/synthesis/evaluation by stimulating the generation of alternative questions e.g. A6, that draw upon both the conceptual constructs of $\mathrm{C}$ and the context underpinning the case study.

From this, students will generate their own alternatives to the questions set which in turn will draw them again into this intellectual and pedagogic process that in turn facilitates them to generate predictions. These predictions are themselves tested within the iterative intellectual and pedagogic process and the underlying pedagogy that will help generate decision-making culminating in best or satisfactory solution generation.

However, some measure should also be given to the target audience. Here, (see Diagram 2) the usage and level of the target audience will influence the type of question initially set by the lecturer. Broadly speaking the shorter the case and the more elementary the target group the more likely is it that draw their questions will be drawn from B Diagram 5 whilst the higher level cases of longer duration will tend to draw their questions from A Diagram 5.

Lecturers should aim therefore, to create a question(s) that naturally fits the real world context so that the issues central to the case study in question are also central to the context. In addition questions should be as free as possible from anything that could cause comprehension difficulties that prevent students from carrying out the task set.

This requires the case writer to have some knowledge of what influences the students' minds and what will cause the right processes to be engaged. The nature of this task of setting trigger questions has the additional problem of making it difficult to retrieve mistakes in compiling questions before the case study is taken. This places a heavy duty of responsibility on the question setter. The solution however, may be relatively simple - Know Your Students.

\section{The Phase}

The Phase represents the amalgamation of the elements that constitute the individual and his/her experiences; the group or class he/she interacts with; and the lecturer and the pedagogy he/she brings to bear on the case study problem and its solution generation. The essence of business case study pedagogy is "to transfer much of the responsibility for learning from the teacher on to the student, whose role, as a result, shifts away from passive absorption toward active construction" (Boehrer, 1990). Simply, the student has to apply theory in 'anger' (see Table 1, questions 1 to 5). He can no longer be passive in the learning process. Consequently, the interaction of these elements in conjunction with the students desire to solve the problem, or from the lecturer's point of view for the student to achieve deep learning, is dependent on a smooth transfer of information and action and reaction 
between Phase and Process and Phase and Syllabus. If this is achieved then analysis, synthesis and evaluation can more readily take place. Furthermore, if deep learning is to be achieved then feedback, in all its guises, is essential (see Table 3, Questions 35 to 37). Once a student has taken an action then it is imperative that feedback whether negative or positive is achieved so review can be undertaken. Here, online, interactive pedagogy and tutorial exercises and quizzes may be used to achieve normative rather than formative learning particularly if the Phase section is firmly embedded in contextual matrix of the case study. The consequence of this is that Kolb's cycle of concrete experiences; observation and reflection; formulation of abstract concepts and generalisations; and testing implications of concepts in new situations may be achieved in a proactive manner.

\section{Syllabus}

Business case studies are generally embedded in a course module and targeted to the appropriate level and position in the course (see Diagram 2). Within this structure they are supported by the course materials which may be delivered in traditional format, interactive format, or a combination of both. Dawson, 1995 warns that innovation in practice can only happen when 'technology push' is coupled with 'user-pull'. Experience from teaching with interactive case studies and developing them in the process, makes one think that "the interactive, multimedia case study tends to reinforce new knowledge and build confidence" (Gallagher 2006) as it is grounded in the course materials which are a blend of traditional and interactive pedagogy that helps to hone the students competences. Consequently, a blended approach to teaching by case study would appear to offer a more efficacious means by which to achieve deep learning objectives. Students, in general, are not interested in the technology per se, but rather in how it is used. Allied to this is the view that what is important, both to the student and the lecturer is not so much what happens at the time when the student is using the technology, but rather how those uses engender deep learning in the student's education (Ehrmann, 2005). The objective for the lecturer is therefore, to have students direct their own learning by formulating and re-formulating questions and taking responsibility for their study (see Table 2, Questions 9 to 14). Interactive materials add to the quality of the learning experience and allow a deeper contextualisation to be achieved through the use of video, animation, self assessment, chat rooms, group support etc. In turn this depth of pedagogic materials and delivery platform allows type A questions to be used more effectively.

\section{The Solution}

Case studies have no definitive solution. “.... solutions should be viewed as a process, or a systematic, contextualised, approach to problem solving. This does not, however, mean that systematizing solution generation will provide good solutions rather, it will allow the materials presented in the case to be listed, prioritised, and analysed in conjunction with the individual's and group's experiential knowledge as a basis for rational decision making." (Gallagher 2006). A number of alternative solutions may be generated from problem identification to final solution selection. Here it may be that the student can choose one best solution from a number of possible solutions. But it is more likely that the end result will culminate in the selection of a satisfactory solution based on the interplay between Problem, Process, Phase and Syllabus. Consequently, students should attempt to identify the pros and cons of each alternative; evaluate them relative to the question set and show what costs and benefits are associated with each alternative. The inferences that are made by the student must in turn be justified but these justifications will be underpinned by the process undergone from initial problem identification to satisfactory solution presentation.

\section{CONCLUSIONS}

It is probably a truism to say that it takes as much effort to answer a bad question as a good one. If this is correct then the onus for the lecturer is to ensure that the question he/she sets is not simply one which is good or bad but rather one that elicits the right or appropriate response from the student.

By their very nature business case studies are rooted in problem-based-learning. They inhabit both an information-rich, and tool-rich environment that combines collaborative learning and action driven learning enhanced through the application of trigger questions that steer the student to address areas, applications and analytical techniques which they might otherwise have missed or avoided. 
Creating these trigger questions is both difficult and time-consuming and care needs to be taken to ensure that the questions are targeted, accurate, unambiguous and suitably challenging. Essentially, they provide a means by which to diminish the 'I don't know' mentality and stimulate critical thinking.

However, a cautionary note should be sounded here. In my experience when giving students their final case study there is often pressure from them to elicit the questions that may have been set. It is a moot point here whether knowledge of the question would do either the test or the student any harm. Personally, I believe that if the trigger questions have been set appropriately then prior knowledge of them will not diminish the efficacy of the case study. However, again in my experience it is far more dangerous to give any hint of the theory the student should examine even in the most general terms. To do so often locks the student into poor thinking and avoidance of more difficult aspects of solution generation as they think that your comment is cast in stone. Nevertheless, if the ground-work of trigger questions has been laid thoroughly, throughout the module, on a progressive basis, then more effective learning and satisfactory solutions can be achieved.

\section{BIBLIOGRAPHY}

1. $\quad$ Bates T. Technology, Open Learning and Distance Education Routledge 1995.

2. Boehrer, J. (1990). Teaching With Cases: Learning to Question. New Directions for Teaching and Learning, 42 41-57.

3. Dawson, S. Never mind solutions: what are the issues? Lessons of industrial technology transfer for quality in health care. Quality in Health Care 1995 4:197-203.

4. Ehrmann, S.C. Asking the Right Question: What Does Research Tell Us About Technology and Higher Learning? http://www.warwick.ac.uk/ETS/interactions/vol3no2/ Accessed October $2^{\text {nd }} .2006$

5. $\quad$ Ewing, D.W. Writing for Results (2nd Edition) (New York, J. Wiley, 1979)

6. Gallagher, J.G. 2004 September: Interactive Case Study Experiences Applied To The Managed Learning Environment, Internet Business Review, 2004, ISSN: 1832-1151

7. Gallagher, J.G. 2006 November: The Journal of Business Case Studies, The Business Case Study: A Suitable Candidate for Blended Learning, ISSN 1555-3353

8. Pegler C, \& Rushworth S. New lamps for old?: Developing a strategy for accommodating new technology within an established DL MBA programme Interactions, Summer term 1999, Vol 3 No.2 - Warwick Business School

9. Sorenson, P. (2000) Drowning in numbers? The need for formative assessment, in Sears, J. \& Sorenson, P., Issues in Science Teaching, London: RoutledgeFalmer, pp.123-132.

10. Taber, K. S. Examining structure and context - questioning the nature and purpose of summative assessment. Seminar presentation to Cambridge International Examinations, University of Cambridge Local Examinations Syndicate, July 2003

11. Wertheim, E.G. A Model for Case Analysis and Problem Solving, College of Business Administration, Northeastern University. Accessed June 2006. http://web.cba.neu.edu/ ewertheim/skills/writovv.htm 
NOTES 